\title{
Absorption and Oxidation of Glucose Polymers of Different Lengths in Young Infants
}

\author{
ROBERT J. SHULMAN, BENNY KERZNER, HOWARD R. SLOAN, THOMAS W. BOUTTON, \\ WILLIAM W. WONG, BUFORD L. NICHOLS, AND PETER D. KLEIN \\ USDA/ARS Children's Nutrition Research Center, Department of Pediatrics, Baylor College of Medicine and \\ Texas Children's Hospital, Houston, Texas 77030, and the Department of Pediatrics, Columbus Children's \\ Hospital, Ohio State University, Columbus, Ohio 43205
}

\begin{abstract}
Because mucosal glucoamylase is most active against glucose polymers less than 10 glucose units in length, longer chain polymers may not be completely absorbed by young infants. In order to investigate this possibility, the absorption and oxidation of ${ }^{13} \mathrm{C}$-rich glucose, short-chain ( 3 to 8 glucose units in length) and long-chain (average length 43 units) glucose polymers (GP) were compared in 12 healthy, 1-month-old infants. Recovery of the GP and glucose in stool was measured by determining the ${ }^{13} \mathrm{C}$ enrichment of stool. The oxidation of the GP was measured by tracing the increase in breath ${ }^{13} \mathrm{CO}_{2}$ after GP were fed. Carbohydrate malabsorbed in the small bowel was assessed by measurement of breath $\mathrm{H}_{2}$, a gas formed from the fermentation of carbohydrate in the colon. Analysis of the infants' stools revealed that one infant excreted $9.7 \%$ of the dose of glucose, another $6.7 \%$ of the dose of short-chain GP, and five infants excreted 2.6 to $18.5 \%$ (mean $8.4 \%$ ) of the dose of long-chain GP. The percent of the administered dose recovered in breath was similar among substrates (mean $=28.7 \%$ of the dose fed). A rise in breath $\mathrm{H}_{2}$ greater than $20 \mathrm{ppm}$ was found in four of the 12 infants after the feeding of glucose, in five of 12 after the short-chain GP, and in six of 12 after the long-chain GP. None of the infants developed diarrhea. The results suggest that healthy young infants do not absorb longchain GP as completely as they absorb short-chain GP. In the absence of pancreatic amylase, salivary amylase and mucosal glucoamylase are sufficient in some young infants to allow for complete digestion of long-chain GP. (Pediatr Res 20: 740-743, 1986)
\end{abstract}

\section{Abbreviations}

GP, glucose polymer

DP, degrees of polymerization

GP commonly are used in infant formulas either as the sole source of carbohydrate or as a caloric supplement. Young infants may not absorb GP completely, because pancreatic amylase activity cannot be detected in the duodenal fluid until 4 to 6

Received November 13, 1985; accepted March 24, 1986.

Address all correspondence and requests for reprints to Robert J. Shulman, M.D., Section of Nutrition and Gastroenterology, Texas Children's Hospital, 6621 Fannin Street, Houston, TX 77030.

This work is a publication of the USDA/ARS Children's Nutrition Research Center, Department of Pediatrics, Baylor College of Medicine and Texas Children's Hospital, Houston, TX. This project has been funded in part with federal funds from the United States Department of Agriculture, Agriculture Research Service under Cooperative Agreement 58-7MNI-6-100. This publication is also supported in part by NIH Grants AM28129, HD 17506, and HD 21878. months of age $(1,2)$. Young infants may digest complex carbohydrates, e.g. GP, through alternative processes, such as the actions of salivary amylase, mucosal glucoamylase, and the colonic bacterial flora. The bacterial flora in the colon is capable of fermenting undigested carbohydrate to hydrogen gas and free fatty acids which then can be absorbed through the colonic mucosa $(3,4)$

Salivary amylase may aid the digestion of complex carbohydrates by infants (5), but the production of this enzyme in young infants is variable and its survival during passage through the stomach is unknown (6). The amount of glucoamylase in the intestinal mucosa of young infants is comparable to that in children, but the extent to which this enzyme can digest GP in vivo remains unclear (7). In addition, glucoamylase has been shown to act preferentially on polymers of $<10$ glucose units (8). As a consequence, the long-chain component ( $>11$ units), which constitute as much as $35 \%$ of the carbohydrate in commercial partial hydrolysates of cornstarch, may not be absorbed completely by young infants. Previous authors who used indirect methods to study glucose polymer utilization, e.g. the rise in serum glucose after an oral load of GP $(9,10)$ or the indirect calculation of the amount of GP in stool (11), have suggested that GP are well absorbed and utilized by young infants. These studies (9-11), however, utilized a mixture of short- and longchain GP. Our study was undertaken to assess the ability of the young infant to absorb and utilize GP of different chain lengths or DP. Two groups of polymers were studied: a short-chain fraction (DP = 3-8), optimal for digestion by glucoamylase, and a long-chain fraction (DP $>43$ ), more suitable for digestion by pancreatic amylase.

Our study exploited the fact that various foodstuffs contain different amounts of the nonradioactive isotope ${ }^{13} \mathrm{C}$. When a subject is maintained on a diet low in ${ }^{13} \mathrm{C}$ and a ${ }^{13} \mathrm{C}$-enriched substrate is then fed, the amount of malabsorbed foodstuff can be calculated directly from the increase in ${ }^{13} \mathrm{C}$-enrichment in feces $(12,13)$. Similarly, the appearance of increased ${ }^{13} \mathrm{CO}_{2}$ in breath marks the oxidation of the enriched foodstuff (12). The appearance of hydrogen in breath was used as a marker of small bowel malabsorption of carbohydrate (4).

\section{METHODS}

Diet. The basal diet consisted of a soy formula (R.C.F., Ross Laboratories, Columbus, $\mathrm{OH}$ ) to which beet sucrose had been added as the sole carbohydrate source to achieve a final concentration of $5 \mathrm{~g} / \mathrm{dl}$. Soy products and beet sucrose have a naturally low ${ }^{13} \mathrm{C}$ content. The test carbohydrates consisted of glucose, short-chain polymers (DP $=3-8$ ), and long-chain polymers (average DP $=43$ ), which were all derived from corn, a foodstuff naturally rich in ${ }^{13} \mathrm{C}$.

The short-chain fraction (DP $=3-8$ ) was prepared from the 
partial hydrolysate of cornstarch by a combination of yeast fermentation and ethanol fractionation (14). The long-chain fraction was prepared by molecular filtration $(14,15)$ of a partial hydrolysate of cornstarch (Polycose, Ross Laboratories). Both short- and long-chain fractions constituted approximately onethird of the original cornstarch hydrolysate.

The infants were maintained on the basal diet throughout the study, except for test days when one of the test carbohydrates was selected at random and substituted for the beet sucrose in the basal formula at a dose of $2 \mathrm{~g} / \mathrm{kg}$. The formula containing the test carbohydrate was given between 0800 and 0900 after a 3- to 5-h fast. Four hours after this feeding, an additional meal of formula containing $2 \mathrm{~g} / \mathrm{kg}$ of the same test carbohydrate was given.

Subjects. Twelve infants were enrolled in the study after informed consent was obtained from their parents. Studies were approved by the Baylor College of Medicine and Texas Children's Hospital Human Investigation Committees. All infants were between 3 and 4 wk of age and had normal perinatal histories, growth, and physical examinations.

Design. The ability of the infants to produce hydrogen was tested on day 0 by administering $0.5 \mathrm{~g} / \mathrm{kg}$ of the nonabsorbable carbohydrate, lactulose. The lactulose was substituted for the beet sucrose in the basal formula. The infants then were sent home with a supply of the basal formuala to which the beet sucrose had been added. They returned on days 3,6 , and 9 at which times they were fed one of the test carbohydrates. Breath samples were collected to determine ${ }^{13} \mathrm{CO}_{2}$ enrichment and $\mathrm{H}_{2}$ production at $-30,-15$, and $0 \mathrm{~min}$ before and every $30 \mathrm{~min}$, up to $4 \mathrm{~h}$, after the initial test meal was administered. Sample collection and calculation of $\mathrm{CO}_{2}$ production rates have been described previously (12). All stools were collected in the diapers from day 3 through day 12 and stored in sealed plastic bags in the subjects' home frezers. Based on information derived from preliminary studies, we scheduled test days at 3-day intervals to insure that both breath and stool ${ }^{13} \mathrm{C}$ enrichments had returned to baseline.

Sample analysis. Stool ${ }^{13} \mathrm{C}$ abundance was determined in the $\mathrm{CO}_{2}$ formed by the combustion of a weighed aliquot of stool after the stool had been lyophilized, homogenized, frozen in liquid nitrogen, and lyophilized once again $(12,13)$. Breath ${ }^{13} \mathrm{CO}_{2}$ enrichment was determined using gas isotope ratio mass spectrometry (16). Breath $\mathrm{H}_{2}$ production and percent $\mathrm{CO}_{2}$ were measured by gas-solid chromatography (17).
Calculations. The calculation of the percent ingested dose of carbohydrate expired in breath or excreted in stool and the calculation of errors have been described previously in detail (12, $13,18)$. Statistical analysis utilized a two-way randomized block analysis of variance or Student's $t$ test as appropriate for the data. An increase in ${ }^{13} \mathrm{CO}_{2}$ in breath or ${ }^{13} \mathrm{C}$ in stool was considered significant if it were greater than twice the SD of the mean baseline value determined while the infant was on the basal formula (12). Malabsorption was detected when the percent dose found in stool exceeded twice the SD of the measured value (12).

\section{RESULTS}

No detectable increase in ${ }^{13} \mathrm{C}$ enrichment of the stools was found in seven of the 12 infants after the administration of the glucose, short- or long-chain GP. Five infants had detectable increases in fecal ${ }^{13} \mathrm{C}$ after the test meals containing the longchain GP (Table 1); the mean increase in ${ }^{13} \mathrm{C}$ enrichment in stool was $8.4 \%$ of the dose fed (Table 1). Malabsorption of the shortchain GP $(6.7 \%$ of the dose fed) was detected in the stool of one infant and $9.7 \%$ of the glucose fed was detected in the stool of a second infant (Table 1).

The time at which a detectable rise in the breath of ${ }^{13} \mathrm{CO}_{2}$ enrichment occurred was $75 \pm 34$ min (mean $\pm \mathrm{SD}$, range 30 to $150 \mathrm{~min}$ ) after the test meals were administered. There were no consistent differences among the test carbohydrates in the time of appearance of the initial increase in breath ${ }^{13} \mathrm{CO}_{2}$ enrichment. The cumulative percent of the dose fed that was oxidized into breath by the time the initial increase in ${ }^{13} \mathrm{CO}_{2}$ enrichment was first detected was simlar for the three carbohydrates (glucose 2.6 \pm 2.5 ; short-chain GP $2.2 \pm 1.7$; long-chain $1.8 \pm 0.9$, mean \pm SD). Similarly, the cumulative percent dose that was oxidized into breath over $4 \mathrm{~h}$ was similar for glucose and the short- and long-chain GP: $31.4 \pm 16.9 \%, 27.3 \pm 6.7 \%, 27.5 \pm 11.5 \%$, respectively (see Table $1, n=10$, samples from two infants were lost becuase of faulty collection tubes).

Three infants failed to produce breath $\mathrm{H}_{2}$ after lactulose was administered, but their results were included because they subsequently produced breath $\mathrm{H}_{2}$ after ingestion of one or more of the test carbohydrates (Table 1). No differences among the test carbohydrates were demonstrated by the number of infants who produced $>20 \mathrm{ppm}$ of $\mathrm{H}_{2}$ over baseline in the $4 \mathrm{~h}$ after the test meals were fed: glucose, four of 12 infants; short-chain GP, five of 12 ; long chain GP, six of 12 . The times (mean \pm SD) for

Table 1. Results of the breath hydrogen tests and cumulative percent dose of the administered carbohydrate recovered in breath and

\begin{tabular}{|c|c|c|c|c|c|c|c|c|c|c|}
\hline \multirow[b]{2}{*}{ Patient } & \multicolumn{4}{|c|}{ Peak hydrogen (ppm) } & \multicolumn{3}{|c|}{$\%$ Dose in breath } & \multicolumn{3}{|c|}{$\%$ Dose in stool } \\
\hline & $\mathrm{L}^{*}$ & $\mathrm{G}^{\dagger}$ & $\mathrm{SC} \ddagger$ & $\mathrm{LC} \S$ & $\mathrm{G}$ & $\mathrm{SC}$ & $\mathrm{LC}$ & $\mathrm{G}$ & $\mathrm{SC}$ & $\mathrm{LC}$ \\
\hline 1 & 28 & 4 & 6 & 21 & 22 & 25 & 23 & $\mathrm{ND \|}$ & ND & ND \\
\hline 2 & 7 & 1 & 17 & 4 & 7 & 19 & 13 & ND & ND & ND \\
\hline 3 & 45 & 135 & 49 & 10 & 33 & ๆ & 26 & ND & ND & $6.1 \pm 2.8^{* *}$ \\
\hline 4 & 12 & 60 & 68 & 9 & 21 & 25 & 21 & ND & $6.7 \pm 2.7$ & $3.7 \pm 1.8$ \\
\hline 5 & 178 & 34 & 36 & 25 & 40 & 20 & 23 & ND & ND & ND \\
\hline 6 & 6 & 46 & 3 & 23 & 18 & 43 & 21 & ND & ND & $11.5 \pm 3.3$ \\
\hline 7 & 194 & 2 & 28 & 3 & 60 & 19 & I & ND & ND & ND \\
\hline 8 & 74 & 2 & 12 & 2 & 31 & 26 & 23 & ND & ND & ND \\
\hline 9 & 24 & 14 & 1 & 36 & 41 & 28 & 36 & ND & ND & $2.6 \pm 1.3$ \\
\hline 10 & 77 & 16 & 51 & 29 & 55 & 32 & 53 & $9.7 \pm 2.1$ & ND & $18.5 \pm 2.2$ \\
\hline 11 & 117 & 4 & 8 & 26 & 21 & 29 & 38 & ND & ND & ND \\
\hline 12 & 245 & 7 & 2 & 11 & 59 & 26 & 23 & ND & ND & ND \\
\hline
\end{tabular}

$*$ L, lactulose.

$\dagger \mathrm{G}$, glucose.

$\ddagger$ SC, short-chain glucose polymers.

$\S \mathrm{LC}$, long-chain glucose polymers.

$\| \mathrm{ND}$, not detectable.

II Samples lost because of faulty collection tubes (see text).

** Mean \pm SD. 
appearance of $>20 \mathrm{ppm}$ breath $\mathrm{H}_{2}$ over baseline were: glucose, $60 \pm 35 \mathrm{~min}$; short-chain GP, $48 \pm 27 \mathrm{~min}$; long-chain GP, 125 $\pm 84 \mathrm{~min}$. Based on regression analysis, we found no correlation between the percent dose of long-chain GP excreted in stool and the peak breath $\mathrm{H}_{2}$.

\section{DISCUSSION}

The results of our investigation reveal that the absorption of long-chain GP was variable and generally less than that of glucose and of the short-chain GP in the healthy infant population studied. The data from our study and from previous experiments help clarify the process of glucose polymer digestion in young infants.

Kerzner et al. (19) have shown in pancreatic amylase-free pocine jejunum that carbohydrate absorption from a partial hydrolysate of cornstarch was less than that from a glucose solution; the bulk of the absorbed carbohydrate had fewer than 12 glucose units. Lebenthal et al. (9) measured the amount of glucose produced from an in vitro incubation of GP and a homogenate of human small intestinal mucosa with and without duodenal fluid (presumably containing pancreatic secretions). These investigations found that in the absence of duodenal fluid, the hydrolysis of GP was diminished. Both studies $(9,19)$ utilized a wide range of GP lengths. Auricchio et al. (20) have shown that glucose polymers containing more than 30 glucose units accumulate in the intestinal lumen of infants younger than 6 months of age fed amylopectin.

Investigations in animals and adults in which the digestion and absorption of specific lengths of GP have been examined have shown that GP that are 6 to 10 glucose units in length are hydrolyzed and absorbed faster than longer polymers $(21,22)$. These data agree with the known preference of glucoamylase for GP chain lengths of 5 to 9 glucose units (8). The results from our study support these findings.

Previous investigators have studied the utilization of GP in young infants by examining clinical tolerance $(9,11,23)$, weight gain $(23)$, or glycemic response $(9,10)$. Unlike our study, however, these investigators $(9-11,23)$ employed cornstarch hydrolysates that were a mixture of both short- and long-chain GP. Although the ${ }^{13} \mathrm{CO}_{2}$ data from our study suggested that similar amounts of short- and long-chain GP were oxidized, the results of the stool analyses revealed that the absorption of the shortchain fraction was greater than that of the long-chain.

Malabsorption of the long-chain GP was detected in the stool analyses of five of the 12 infants. This finding contrasts with the observations of Kien et al. (11) who fed premature infants a formula that contained either lactose or lactose and GP in a 50/ 50 ratio. The infants' stools were analyzed for nitrogen, fat, and total energy excreted. The carbohydrate energy absorption was calculated by difference. The investigators found no differences in the coefficient of carbohydrate energy absorption between the two types of feedings, which suggests that the GP were well absorbed.

Our results are not directly comparable with those of Kien et al. (11) because, as in the studies previously cited $(9,10,23)$, Kien et al. fed a mixture of short- and long-chain GP. In addition, we specifically measured carbon derived from the test carbohydrate.

One infant had detectable malabsorption of both glucose and long-chain GP (Table 1). The reason for the incomplete absorption of glucose is unclear as the infant had no evidence of intestinal dysfunction. A caretaker other than the mother may have fed this infant a foodstuff different from the basal diet, but we were unable to prove this possibility. Because glucose was the last carbohydrate tested in this infant, no further breath collections were made after the infant went home, although stools were collected. Thus, we could not examine the baseline breath ${ }^{13} \mathrm{CO}_{2}$ enrichment which would have reflected a change in the ${ }^{13} \mathrm{C}$ enrichment of the diet.
Breath $\mathrm{H}_{2}$ measurements have been used to demonstrate the fermentation of unabsorbed carbohydrate by the colonic flora (4). In view of the results of the fecal analyses in our study, more infants would have been expected to have produced $>20 \mathrm{ppm}$ breath $\mathrm{H}_{2}$ after the long-chain GP were fed than after either the glucose or short-chain GP. Our inability to find any differences may have been due to the small number of infants studied.

In summary, our results demonstrate that long-chain GP are not absorbed as completely as short-chain GP by some young infants. Other infants who also are presumed to make no pancreatic amylase, nonetheless, can digest long-chain GP effectively. A number of mechanisms may account for the difference in the infants' ability to digest and absorb the long chain GP, e.g. salivary amylase, pancreatic amylase, the colonic flora, and mucosal glucoamylase. The spectrum of activity of salivary amylase is similar to that of pancreatic amylase (6). Recent evidence suggests that some salivary amylase activity may survive passage through the stomach (7). The level of salivary amylase, which is generally low at 1 month of age, is variable among infants. Because of this variability, salivary amylase may contribute to GP digestion in individual infants $(6,7)$. Although levels of pancreatic amylase at this age also may vary among infants, most studies suggest that the levels are too low at 1 month of age to contribute significantly to the digestion of GP $(1,2)$. The colonic bacterial flora plays a major role in salvaging carbohydrate malabsorbed in the small bowel (3). The results of breath $\mathrm{H}_{2}$ studies in these 1-month-old infants after the administration of the nonabsorbable carbohydrate, lactulose, suggest that the ability of the colonic flora to ferment carbohyrate is variable. As a consequence, interindividual variability in the fecal excretion of the long-chain GP would be expected if the carbohydrate were not absorbed completely in the small bowel. Thus, we speculate that the diminished absorption of the long-chain GP primarily reflects the lack of preference of glucoamylase for the long-chain fraction and variability in the ability of the colonic flora of infants this age to ferment carbohydrates. Although the absolute amount of energy lost in the stools of the study infants was not great, infants who have low levels of salivary amylase (i.e. premature infants), mucosal glucoamylase (i.e. infants with gastroenteritis), or colonic bacterial flora (i.e. after antibiotics) may be less able to digest long-chain, and even short-chain, GP than their healthy counterparts.

Acknowledgments. The authors thank Judy Hopkinson, Ph.D. and Carolyn Heinz for patient recruitment; the dietary staff of the Clinical Research Center of Texas Children's Hospital for formula preparation; Dorothy Johnson, R.N., Rebecca Hethcock, R.N., and Lori Wise, R.N., for sample collection; Mary Nelson, Kelly Lobb, and Michelle Steinfeld for sample analysis; Constance Seckel and Anton Ailabouni for preparing the substrates; E. Roseland Klein for editorial review; E. O'Brian Smith, $\mathrm{Ph} . \mathrm{D}$. and Charles S. Irving, Ph.D. for assistance in data analysis; and Sandy Perez for manuscript preparation. The generosity of Ross Laboratories in supplying the R.C.F. formula and the partial hydrolysate of cornstarch is appreciated.

\section{REFERENCES}

1. Klumpp TG, Neale AV 1930 The gastric and duodenal contents of normal infants and children. Am J Dis Child 40:1215-1229

2. Kamaryt Von J, Fintajslova O 1970 Die Entwicklung der Speichel and Pankreas-Amylase bei Kindern im Laufe des ersten Lebensjahres. Z Klin Chem Klin Biochem 8:564-566

3. Bond JH, Currier BE, Buchwald H, Levitt MD 1980 Colonic conservation of malabsorbed carbohydrate. Gastroenterology 78:444-447

4. Solomons NW, Viteri F 1978 Development of an interval sampling hydrogen breath test for carbohydrate malabsorption in children: evidence of a circadian pattern of breath $\mathrm{H}_{2}$ concentration. Pediatr Res 12:816-823

5. Hodge C, Lebenthal E, Lee PC, Topper W 1983 Amylase in the saliva and in the gastric aspirates of premature infants: its role in glucose polymer hydrolysis. Pediatr Res 17:998-1001

6. Sevenhuysen GP, Holodinsky C, Dawes C 1984 Development of salivary 
alpha-amylase in infants from birth to 5 months. Am J Clin Nutr 39:584588

7. Lebenthal E, Lee PC 1980 Glucoamylase and disaccharidase activities in normal subjects and in patients with mucosal injury of the small intestine. $J$ Pediatr 97:389-393

8. Kelly JJ, Alpers DH 1973 Properties of human intestinal glucoamylase. Biochem Biophys Acta 315:113-120

9. Lebenthal E, Heitlinger L, Lee PC, Nord KS, Hodge C, Brooks SP, George D 1983 Corn syrup sugars: in vitro and in vivo digestibility and clinical tolerance in acute diarrhea of infancy. J Pediatr 103:29-34

10. Cicco R, Holzman IR, Brown DR, Becker DJ 1981 Glucose polymer tolerance in premature infants. Pediatrics 67:498-502

11. Kien CL, Sumners JE, Stetina JS, Heimler R, Grausz JP 1982 A method for assessing carbohydrate energy absorption and its application to premature infants. Am J Clin Nutr 36:910-916

12. Shulman RJ, Wong WW, Irving CS, Nichols BL, Klein PD 1983 Utilization of dietary cereal by young infants. J Pediatr 103:23-28

13. Schoeller DA, Lein PD, MacLean WC, Watkins JB, Van Santen E 1981 Fecal ${ }^{13} \mathrm{C}$ analysis for the detection and quantitation of intestinal malabsorption. J Lab Clin Med 97:439-448

14. Sloan HR, Kerzner B, Scobell HD, Strohl WR, Seckel C, Ailabouni A 1985 Large scale production of glucose oligomers and polymers for physiological studies in humans. Prep Biochem 15:229-279

15. Sloan HR, Kerzner B, Seckel C 1984 Large scale preparation of selected glucose oligomers and polymers by gel filtration chromatography. Prep Biochem 14:245-256

16. Schoeller DA, Klein PD 1979 A microprocessor controlled mass spectrometer for the fully automated purification and isotopic analysis of breath carbon dioxide. Biomed Mass Spectrom 6:350-355

17. Niu H, Schoeller DA, Klein PD 1979 Improved gas chromatographic quantitation of breath hydrogen by normalization to respiratory carbon dioxide. $\mathbf{J}$ Lab Clin Med 94:755-763

18. Craven BR, Lark PD, Bosworth RCL 1968 The Handling of Chemical Data. Pergamon Press, Oxford, England

19. Kerzner B, Sloan HR, Haase G, McClung HJ, Ailabouni AH 1981 The jejunal absorption of glucose oligomers in the absence of pancreatic enzymes. Pediatr Res 15:250-253

20. Auricchio S, Pietra DD, Vegnente A 1967 Studies on intestinal digestion of starch in man. II. Intestinal hydrolysis of amylopectin in infants and children. Pediatrics 38:853-862

21. Kerzner B, Sloan HR, McClung HJ, Chidi CC 1986 Absorption of glucose polymers in canine jejunum deprived of pancreatic amylase. Am J Physiol (in press)

22. Jones BJM, Brown BE, Loran JS, Edgerton D, Kennedy JF, Stead JA, Silk DBA 1983 Glucose absorption from starch hydrolysates in the human jejunum. Gut 24:1152-1160

23. Raffles A, Schiller G, Erhardt P, Silverman M 1983 Glucose polymer supplementation of feeds for very low birthweight infants. Br Med J 286:935-936 